\title{
Induced over voltage test on transformers using enhanced Z-source inverter based circuit
}

\author{
Geno Peter, Anli Sherine*
}

\begin{abstract}
The normal life of a transformer is well above 25 years. The economical operation of the distribution system has its roots in the equipments being used. The economy being such, that it is financially advantageous to replace transformers with more than 15 years of service in the second perennial market. Testing of transformer is required, as its an indication of the extent to which a transformer can comply with the customers specified requirements and the respective standards (IEC 60076-3). In this paper, induced over voltage testing on transformers using enhanced Z source inverter is discussed. Power electronic circuits are now essential for a whole array of industrial electronic products. The bulky motor generator set, which is used to generate the required frequency to conduct the induced over voltage testing of transformers is nowadays replaced by static frequency converter. First conventional Z-source inverter, and second an enhanced Z source inverter is being used to generate the required voltage and frequency to test the transformer for induced over voltage test, and its characteristics is analysed.

K e y w or d s: transformer, motor generator, Z-source inverter, static frequency converter
\end{abstract}

\section{Introduction}

The advancements in induced over voltage testing is done by replacing the space consuming, bulky and noisy motor generator set with power electronics based frequency generator[16]. An enhanced Z-source inverter based power electronics circuit is used to control and generate the required frequency, to test the transformer for induced over voltage test. This new concept is being tested and analyzed with the existing conventional Z-source inverter based system. Along with the static converter, a $\mathrm{Z}$ source network is added, and its performance is analyzed. The Z-source inverter has a unique impedance network which couples the converter main circuit to the power source, thus providing unique features that cannot be obtained in the traditional voltage-source and currentsource inverters where a capacitor and inductor are used, respectively. The Z-source inverter overcomes the conceptual and theoretical barriers and limitations of the traditional voltage source inverter and current source inverter and provides a novel power conversion concept. The Zsource concept can be applied to all DC/AC, AC/DC, $\mathrm{AC} / \mathrm{AC}$, and $\mathrm{DC} / \mathrm{DC}$ power conversions, [1].

\section{Double voltage double frequency test}

The induced over voltage test is also called as double voltage double frequency test. This test is carried out at a test frequency which is twice the rated frequency at which the equipment is supposed to operate during its life time, so that the core does not saturate. The transformer is fed with double voltage to test the withstand capability, for higher voltages due to lightning surges and faults in transformer [17]. This is a poly phase test for three phase transformer and single phase test for single phase transformers [18].

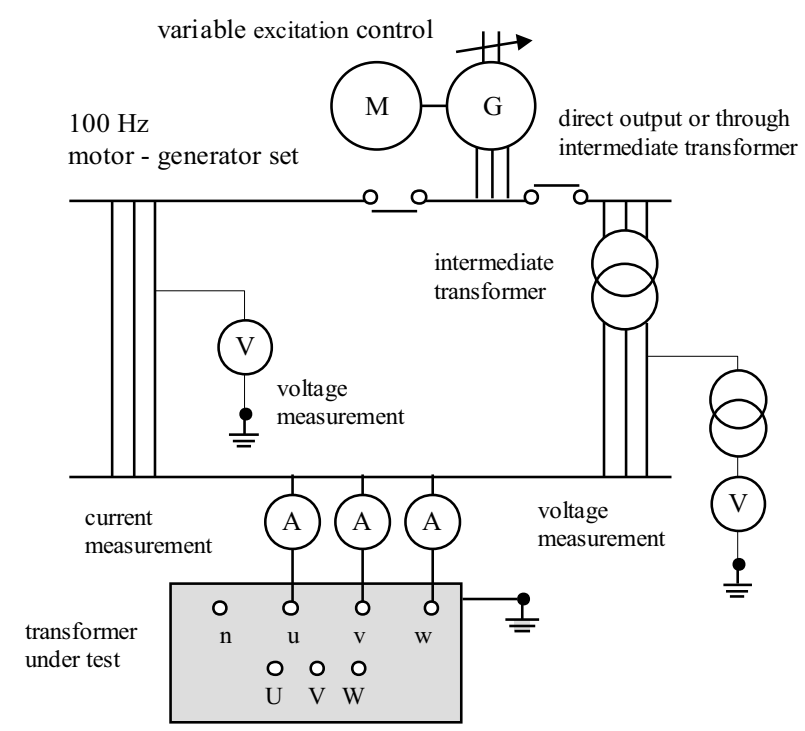

Fig. 1. Test set up using motor generator set

2.1 Purpose of induced over voltage test on transformers

The purpose of conducting induced over voltage test on transformers is to check the electrical healthiness and suitability of the transformer for the intended voltage application. This test is done by application of test over

* School of Engineering and Technology, University College of Technology Sarawak, 868 Persiaran Brooke, 96000 Sibu ,Sarawak, Malaysia, genopeter@gmail.com 


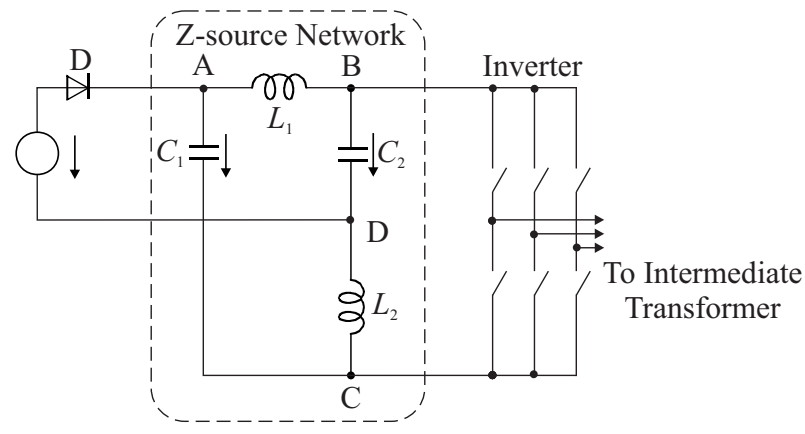

Fig. 2. Conventional ZSI

voltages as prescribed by the standards [19]. This test verifies the inter- turn insulation strength, the insulation strength between adjacent turns in the form of enamel on copper, paper covering, and interlayer insulation is case of foil winding. Clearances between phases of outside winding on the active part- inter-phase clearances, External clearances between busing of same phase and to bushing of other windings [2]. The power source is a high frequency generator, whose output is directly connected to the transformer or through intermediate transformer as shown in Fig. 1, [2].

\subsection{Test source}

The power source should be efficient enough to feed the magnetic loss at twice the rated frequency of the transformer under test which has normally a poor power factor. The frequency should be twice the nominal frequency. The current consumed by the transformer would be the magnetizing currents and the charging currents at twice the rated frequency. The current loaded depends on many factors like the insulation strength, the voltage class, frequency, magnetic flux density etc., Standard stipulate that the applied voltage should be double the nominal voltage of the winding, this is the reason why twice the frequency is needed as the core will saturate with the rated frequency. The minimum frequency is 100 $\mathrm{Hz}$ and maximum permitted frequency is $400 \mathrm{~Hz}$ [20].

\subsection{Disadvantages of using motor generator set}

If an induction motor is used as a prime mover for the generator, the speed drops during load conditions and hence the output frequency also drops. In such cases the duration of the test must be suitably increased to comply with the condition specified in the standard. IEC 600763 , specifies the test duration for the induced over voltage test, and is given as

$$
T=T_{C} \frac{f_{R}}{f_{T}}
$$

with $T_{C}=120 \mathrm{~s}$.

\section{Z-source inverter for double voltage double frequency test}

Inverters have been used for power conversion in high power applications. Power converters are commonly based on a VSI connected to the supply network, operated to achieve objectives such as power flow regulation or power factor optimization by regulating the current into the grid using schemes such as synchronous frame controllers, hysteresis-based strategies [3]. As shown in Fig. 2, the ZSI employs an impedance network which couples the converter main circuit to the power source, load, or other converters [8]. This output is connected to an intermediate transformer which in turn feeds the test transformer [4].

\subsection{Capacitor voltage stress in Z-source}

A high voltage stress is imposed on Z-source capacitor and inverter-bridge when a large shoot-through duty ratio is applied. Therefore, the conventional ZSI has limitation on providing both a high boost factor (B) and a high output voltage simultaneously. The peak DC-link voltage across the inverter bridge of the traditional ZSI can be expressed as

$$
V_{i n}=B V_{D C}=\frac{T_{1}}{T_{1}-T_{0}} V_{D C}
$$

while $T$ is the total time period, $T_{1}$ is the time period of non-shoot-through state, and $T_{0}$ is the time period of the shoo-through state. Above, $V_{\mathrm{DC}}$ is the input DC voltage, and $B$ is the boost factor of the circuit. The current ripples and the voltage ripples in same in both the topologies [9]. The current across the inductor in the existing topology decreases during the non-shoot through state. In the traditional topology, The Z-source capacitor voltage is determined by

$$
V_{C}=\frac{1-d}{1-2 d} V_{D C}
$$

where $V_{\mathrm{C}}$ is the capacitor voltage; $d=T_{0} / T$ is the duty ratio during the shoot through state. $V_{\mathrm{C}}$ is never less than $V_{\mathrm{DC}}$, thus presenting a high capacitor voltage stress across the $\mathrm{Z}$-source. The capacitor voltage is equal to the supply voltage when $d=0$ in the Z-source circuit. The inverter gains maximum shoot-through time which in turn gives the inverter higher boost factor, according to (2). It can boost the output voltage by introducing shoot through operation mode, which is forbidden in traditional voltage source inverters. The boost factor is determined by the shoot-though duty cycle. 


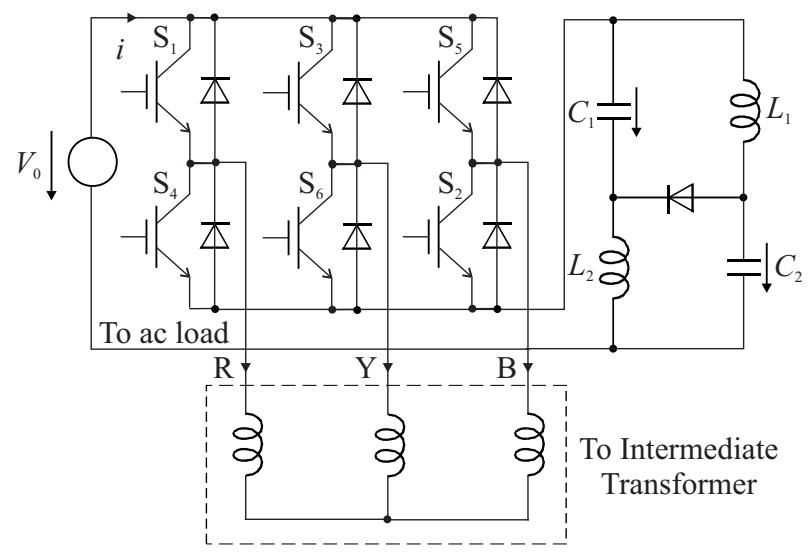

Fig. 3. Enhanced Z source inverter topology for transformer testing

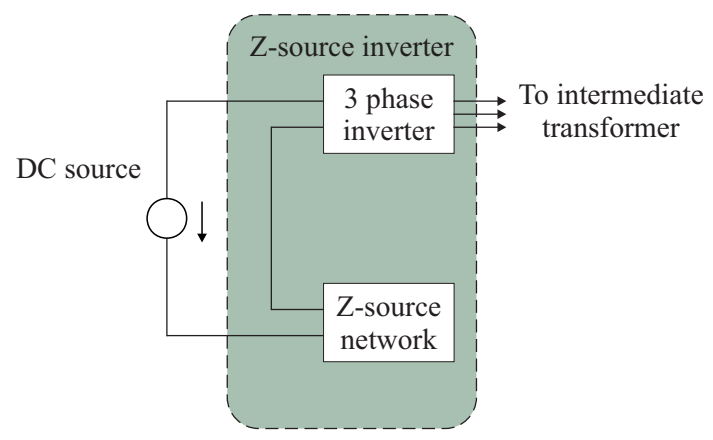

Fig. 4. Enhanced Z-source inverter topology

\section{Enhanced Z-source inverter topology}

The parts of enhanced ZSI is exactly the same as the conventional one. The only difference is that the positions of the diode and Inverter Bridge are exchanged and their connections are also reversed [12]. The voltage polarity of $\mathrm{Z}$ source capacitors in the enhanced ZSI what's left the same as the input voltage polarity; hence, the capacitor voltage polarity might be decreased to a respectable level to get the same boost voltage. The improved Z-source topology has inborn inrush-current confinement capability contrasted with the conventional ZSI, in light of the fact that there is no current path at startup [5].
The proposed enhanced ZSI with reduced capacitor voltage stress and eliminate the possibility of the DClink voltage severance, simplify the Z-source network inductor and controller design, increase the inverter section pattern, thus, decrease the capacitor voltage stress by changing the magnitude and distribution of the harmonics and then decrease the iron loss of the transformer that use a ZSI [15]. The commutation stage of proposed enhanced Z-source inverter is categorized into open state, active state and shoot through state. During the commutation stage, the current flows through three phases.

\section{Simulation using MATLAB}

The conventional and the proposed enhanced Z-source inverter for induced over voltage test on transformer, was implemented in MATLAB platform. Implementation parameters of proposed system are summarized in Tab. 1.

\subsection{Performance analysis of conventional and enhanced ZSI}

The conventional Z-source inverter was tested on MATLAB simulation platform and the different output parameters were analyzed. From the simulation results, the performance of the conventional Z-source inverter is analyzed by loading the test transformer at $800 \mathrm{~V}, 150 \mathrm{~Hz}$ for 40 seconds.

Figure 5, illustrates that the performance analysis of the conventional system, the performance of the conventional system can be analyzed based on the factors such as current, voltage and frequency. A constant or uniform non-varying input should be applied to the system. The graph is plotted at the time interval of 0 to $2 \mathrm{~s}$. In the starting stage an oscillation occurs in the system from 0 to $0.25 \mathrm{~s}$. Then it moves slightly and attains a constant voltage and frequency at $0.89 \mathrm{~s}$. The voltage level also ranges at the same level as the current. The typical wave form is indicated in the simulation graph results from the initial condition which is zero to the steady state condition. The duty ratio varies periodically hence small oscillations is seen in the current and voltage waveforms. The small harmonics related with the yield phase voltage and

Table 1. Implementation parameters of proposed system

\begin{tabular}{lcc}
\hline Apparatus & Parameters & Values \\
\hline Transformer & Winding 1 Voltage, Resistance, Inductance & $800 \mathrm{~V}, 2 \mathrm{~m} \Omega, 80 \mathrm{mH}$ \\
& Winding 2 Voltage, Resistance, Inductance & $800 \mathrm{~V}, 2 \mathrm{~m} \Omega, 80 \mathrm{mH}$ \\
\hline Converters and DC bus & Snubber Resistance & $1200 \Omega$ \\
& Snubber Capacitance & $22 \mathrm{nF}$ \\
& ON State Resistance of Diode & $2 \mathrm{~m} \Omega$ \\
& Forward Voltage & $1.2 \mathrm{~V}$ \\
DC Bus Capacitor & $2.2 \mu \mathrm{F}$ \\
& Braking Resistance of Chopper & $9 \mathrm{kHz}$ \\
Braking Frequency of Chopper & $400 \mathrm{~V}$ \\
Activation Voltage & $300 \mathrm{~V}$ \\
\hline
\end{tabular}




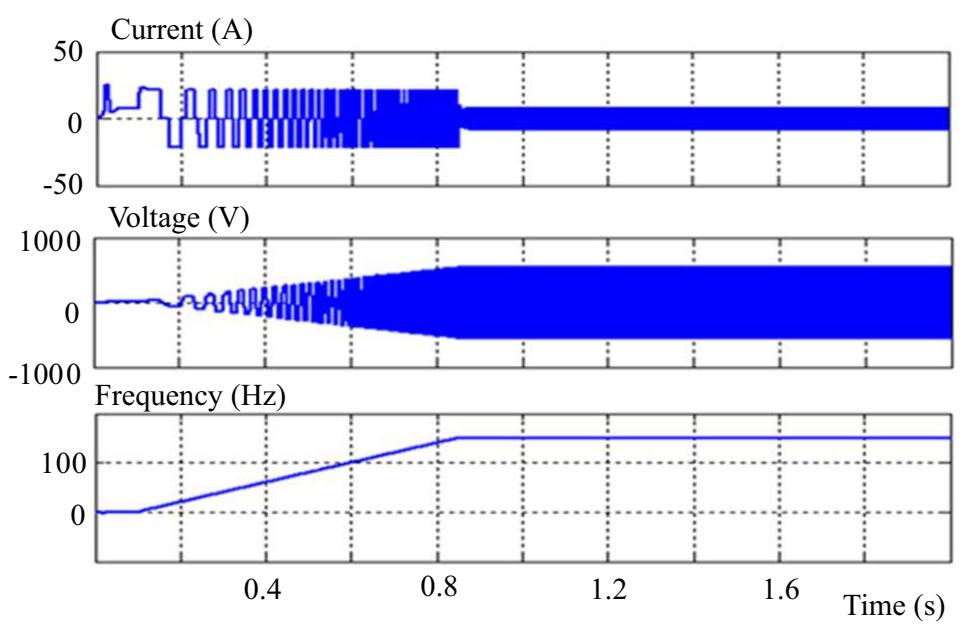

Fig. 5. Conventional ZSI waveforms

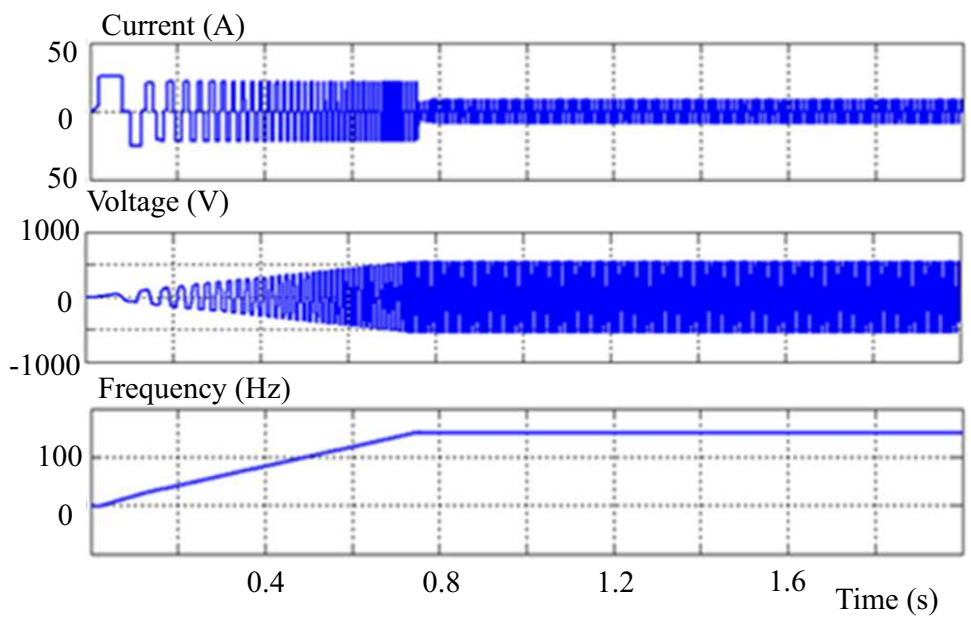

Fig. 6. Enhanced ASI

the voltage oscillation from the capacitor, it is seen that the force quality at the maximum support control condition is not as great as that under the normal help control condition [11]. In the conventional $\mathrm{Z}$ source inverter the test transformer is fed with test voltage and frequency at $0.89 \mathrm{~s}$.

The performance analysis of the enhanced ZSI is shown in Fig. 6. The oscillations and startup duration occurring in voltage, current and the frequency is the same when compared to the conventional system.

But the performance obtained in the enhanced system is higher. The typical wave form indicated is the simulation graph results obtained between the zero initial conditions to the steady state condition [13]. Small oscillations are introduced in the voltage and current as the duty cycle varies periodically. Hence it is seen that the force quality at the maximum support control condition is not as great as that under the normal help control condition as small harmonics is seen in the yield phase voltage and the capacitor voltage. In the proposed enhanced $\mathrm{Z}$ source inverter, the test transformer is fed with test voltage and frequency at $0.79 \mathrm{~s}$. The enhanced Z-source inverter can boostbuck voltage, minimize component count, increase efficiency, and reduce cost.

\section{Comparison analysis}

From the above performance analysis graphs the comparison performance of the conventional and enhanced system can be analyzed. The performance of the enhanced ZSI is much greater than the conventional system. The red color in the graph represents the enhanced system and the blue color lines represent the conventional drive system [7]. The frequency level of the conventional system takes more time to startup when compared to the enhanced ZSI. The startup interval of the conventional system takes much more time when compared to the enhanced system [14]. The comparison graphs for both the cases of conventional and enhanced system are shown below. For comparative analysis the frequency is analyzed up to 2 seconds.

The performance of the enhanced ZSI is evaluated based on voltage and the duty ratio which are illustrated in Fig. 8, and Fig. 9. The ratio of $V_{\mathrm{c}}$ (capacitor voltage) and $V_{\mathrm{o}}$ (output voltage) is analyzed with respect to time and then with duty ratio. Concerning the Z-source inverter and its stable operation, it depends on the capacitor discharge voltage level $\left(V_{\mathrm{c}}\right)$ and the output voltage $\left(V_{\mathrm{o}}\right)[15]$. The voltage relation for a time period of $1 \mathrm{sec}-$ 


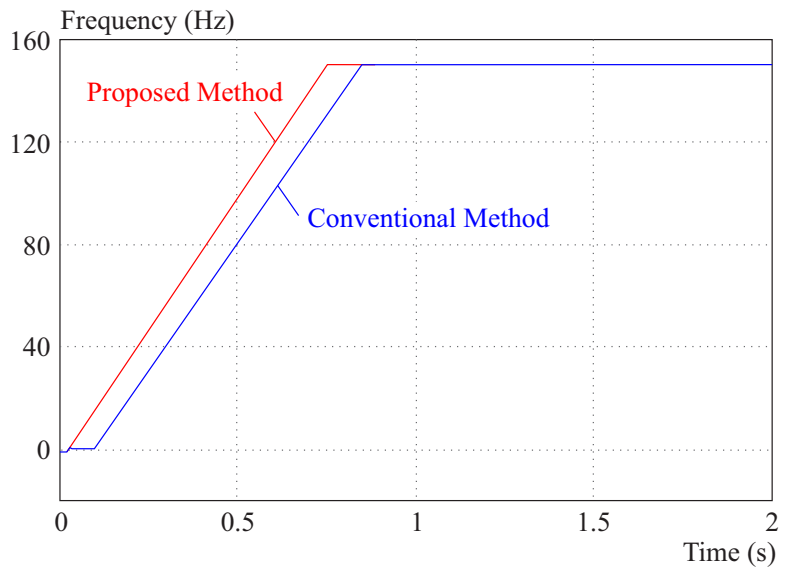

Fig. 7. Comparison performance of enhanced and conventional system with respect to frequency

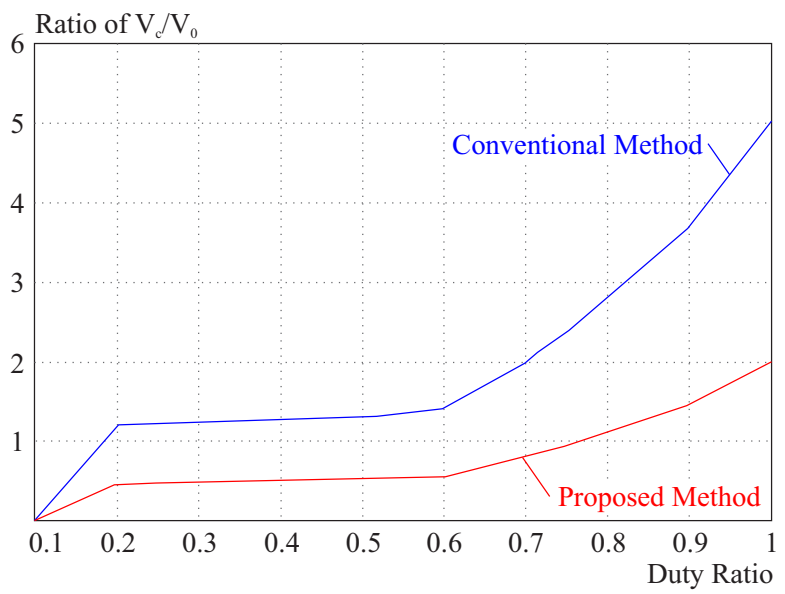

Fig. 9. Performance of ratio between capacitor and output voltage with respect to duty ratio

Table 2. Comparison of test results: $T_{\mathrm{S}}$ - time in seconds at which voltage $(800 \mathrm{~V})$ and frequency $(150 \mathrm{~Hz})$ are stable, and capacitor stress-effects

\begin{tabular}{lcc}
\hline Z-source & $T_{\mathrm{S}}$ & $\begin{array}{c}\text { Discharge loss } \\
\text { output }\end{array}$ \\
\hline Conventional & 0.84 & $\begin{array}{c}\text { high } \\
\text { non linear } \\
\text { low } \\
\text { linear }\end{array}$ \\
\hline
\end{tabular}

ond is shown in Fig. 9. During this period, the voltage of enhanced system is linear hence the discharging loss is minimum [6]. The enhanced Z-source capacitor voltage decreases with respect to output voltage while maintaining the same voltage boost which makes the test voltage and frequency stable for the test transformer.

\section{Field test results}

The practical test was conducted on distribution transformers of two different ratings.

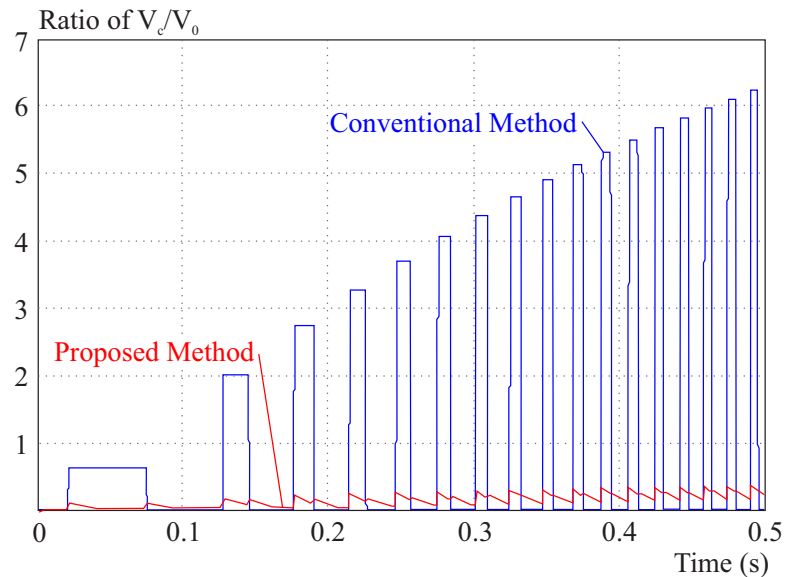

Fig. 8. Performance of ratio between capacitor and output voltage with respect to time

Test Transformer TR 1: Distribution Transformer ratings: 3 phase, $1000 \mathrm{kVA}, 11 \mathrm{kV} / 400 \mathrm{~V}, 50 \mathrm{~Hz}$. The enhanced Z-source static frequency inverter output is fed as input to the intermediate transformer of rating $500 \mathrm{kVA}$, and voltage and frequency control was done from the control panel of the system. Table 3 gives the test results of induced over voltage test on test Transformer 1, fed through an intermediate transformer using an enhanced static frequency inverter.

Test Transformer TR 2: Distribution Transformer ratings: 3 phase, $1500 \mathrm{kVA}, 11 \mathrm{kV} / 433 \mathrm{~V}, 50 \mathrm{~Hz}$. Table 3 gives the test results of induced over voltage test on test Transformer 2, fed through an intermediate transformer using an enhanced static frequency inverter.

The Test transformer is said to have passed the test, as no insulation failure in the windings has occurred during $40 \mathrm{~s}$. From Tab. 3, it is noticed that the measured voltage and current readings has no abrupt changes throughout the test.

Table 3. Transformers test results

\begin{tabular}{lcc}
\hline & TR 1 & TR 2 \\
& $11 \mathrm{kV} / 400 \mathrm{~V}$ & $11 \mathrm{kV} / 433 \mathrm{~V}$ \\
rated kVA & 1000 & 1500 \\
phase voltage (V) & 800 & 866 \\
frequency $(\mathrm{Hz})$ & 150 & 100 \\
& Measured & current $\quad(\mathrm{A})$ \\
\hline $\mathrm{U}$ & 3.2 & 4.4 \\
$\mathrm{~V}$ & 2.9 & 3.7 \\
$\mathrm{~W}$ & 3.3 & 4.3 \\
\hline Test duaration & $40 \mathrm{~s}$ & $60 \mathrm{~s}$ \\
& passed & passed
\end{tabular}

\section{Conclusion}

The Z-source inverter has a unique LC network which couples the main inverter circuit to the diode front end. As results, the enhanced Z-source inverter system provides a reduced capacitor voltage stress, inrush current 
and extends output voltage range. The proposed enhanced Z-source inverter for induced over voltage test on transformer, was implemented in MATLAB platform. Then, using the simulated results, the frequency was compared with conventional Z-source inverter. In enhanced Z-source inverter, the voltage stress is reduced and the voltage ripples across the capacitor is reduced thereby a constant frequency is generated, which is an important parameter for induced over voltage test on transformers hence the efficiency is high. For simulation result, the test transformer was feed with $800 \mathrm{~V}, 150 \mathrm{~Hz}$ for a duration of 40 seconds and the comparative analysis is tabulated in Table 2. It is seen the Proposed enhanced Z source static Inverter attains a stable voltage and frequency much earlier compared to the conventional one. The field test was conducted on transformers of two different ratings. First, Test Transformer TR 1 was feed with $800 \mathrm{~V}$ at $150 \mathrm{~Hz}$ for a duration of 40 seconds and the result is tabulated. Secondly, Test Transformer TR 2 was feed with $866 \mathrm{~V}$ at $100 \mathrm{~Hz}$ for a duration of 60 seconds as per the standards (IEC 60076-3), and the result is tabulated. It is seen, in both the cases the voltage and frequency was constant throughout the test duration. The working of the circuit was found to be satisfactory.

\section{Acknowledgement}

The authors wish to thank Prof Ir Dr Mohd Shahril Osman, Dean, School of Engineering \& Technology, UCTS, Sarawak and Ir Dr Abdul Razak bin Yaacob, Head of programme (EEE), UCTS, Sarawak for their support and encouragement.

\section{REFERENCES}

[1] F. Z. Peng, "Z-source inverter", IEEE Transactions on Industry Applications, vol. 39, no.2, pp. 504-510, 2003.

[2] Geno and Peter, "A Review about testing of distribution transformer", International Journal of Advancements Technology, vol. 2, no.1, pp. 165-177, 2011.

[3] Y. [3], S. Tang, J. Xie and Wei, "Grid-tied photovoltaic system with series Z-source inverter", IET Renewable Power Generation, vol. 7, no.3, pp. 275-283, January 2013.

[4] F. [4], P. C. Gao, F. Loh, and and C. J. Blaabjerg and Gajanayake, "Operational analysis and comparative evaluation of embedded Z-Source inverters, ", IEEE Power Electronics Specialists Conference, 2008.

[5] Z. [5] and Rymarski, "The discrete model of the power stage of the voltage source inverter for UPS, ", International Journal of Electronics, vol. 98, no.10, pp. 1291-1304, 2011.

[6] G. E. C. H. Ma, "”, High Power, High Voltage, Audio Frequency Trans-Former Design Manual, January 1963.

[7] H. [7], A. S. Mohseni, J. Akmal, E. Jadidian, E. Hashemi, A. Agheb, A. Naieny and K. Niayesh and Ghorbandaeipour, "Induced voltage test of distribution transformers using static frequency inverters", IEEE/PES Transmission and Distribution Conference and Exposition, 2008.

[8] M. [8], F. Shen and Peng, "Operation modes and characteristics of the Z-source inverter with small inductance", Fourtieth IAS Annual Meeting, Conference Record of the Industry Applications Conference, 2005
[9] S. [9] and Thangaprakash, "Unified MPPT Control Strategy for Z-Source Inverter Based Photovoltaic Power Conversion Systems", Journal of Power Electronics, vol. 12, no.1, pp. 172-180, 2012.

[10] M. Shen, J. Wang, A. Joseph, F. Peng, L. Tolbert and D. Adams, "Maximum constant boost control of the Z-source inverter", Conference Record of the IEEE Industry Applications Conference, 39th IAS Annual Meeting, 2004.

11] O. [11], J. V. Ellabban, P. Mierlo and Lataire, "Experimental Study of the Shoot-Through Boost Control Methods for the Z-Source Inverter", EPE Journal, vol. 21, no.2, pp. 18-29, 2011.

12] M. Zhu, K. Yu and F. L. Luo, "Topology analysis of a switchedinductor Z-source inverter", 5th IEEE Conference on Industrial Electronics and Applications, 2010.

13] D. [13], S. L. Kalyanraj and Prakash, "Design and performance analysis of different current control strategies of voltage source inverter", International Conference on Power, Energy and Control (ICPEC), 2013.

14] X. Fang, "Maximum boost control of the current-fed Z-source inverter", IEEE International Conference on Industrial Technology, 2008.

15] W. Qian, F. Z. Peng and H. Cha, "Trans-Z-Source Inverters", IEEE Transactions on Power Electronics, vol. 26, no.12, pp. 3453-3463, 2011.

16] S. Digby and H. J. Sim, Power Transformers Electrical Engineering Handbook Electric Power Transformer Engineering, Second Edition, 2007.

[17] M. Duval, F. Langdeau, P. Gervais and G. Belanger, "Influence of paper insulation on acceptable gas-in-oil levels transformers", , Conference on Electrical Insulation and Dielectric Phenomena.

[18] H. Jackson and K. Ripley, "Transformer Processing and Testing", Modern Power Transformer Practice, pp. 153-186, 1979.

[19] "Recommended Dielectric Tests and Test Procedures for Converter Transformers and Smoothing Reactors IEEE Working Group on Dielectric Tests for HVDC Stressed Transformers and Reactors", IEEE Power Engineering Review, vol. PER-6, no.7, pp. 48-49, 1986.

[20] "Test Execution", Testing SAP R/3: A Managers Step-by-Step Guide, pp. 267-283, 2015.

Received 13 April 2017

Geno Peter completed the Bachelor of Engineering (BE) in Electrical \& Electronics Engineering from Bharathiar University, India subsequently completed Master of Engineering (ME) in Power Electronics and Drives from Karunya University, India, then received the Doctor of Philosophy (PhD) in Electrical Engineering from Anna University, India. He started his career as Test Engineer with General Electricals (Transformer Manufacturing Company) in India, subsequently worked with Emirates Transformer and Switchgear, Dubai as Test Engineer and then with Al-Ahleia Switchgear Company, Kuwait as Quality Assurance Engineer. He is a trained person to work on HAEFELY, Impulse Test system, Switzerland. He is a trained person to work on Morgan Schaffer, Dissolved Gas Analyser Test system, Canada. His research interests are in Transformers, Power Electronics, Power Systems and Switchgears.

Anli Sherine completed the Bachelor of Technology (BTech) in Information Technology from Anna University, India subsequently completed Master of Engineering (ME) in Computer Science Engineering from Anna University, India. She has worked as assistant professor with reputed Colleges in India and as Software Engineer in Kuwait. Currently she is working as a lecturer with UCTS, Malaysia 